\title{
CURSO INTRODUTÓRIO PARA AS EQUIPES BÁSICAS DO PROGRAMA DE SAÚDE DA FAMÍLIA
}

\author{
Helena Hemiko Iwamoto' \\ Darlene Mara dos Santos Tavares ${ }^{1}$ \\ Iranilde José Messias Mendes²
}

\section{INTRODUÇÃO}

O Governo Federal reconhecendo a distância existente entre os avanços nos direitos sociais constitucionalmente garantidos e a efetiva oferta dos serviços públicos, instituiu em 1994 o Programa de Saúde da Família (PSF) como uma estratégia de reorganização da Atenção Básica à Saúde desencadeada com a criação, em 1988, do Sistema Único de Saúde (BRASIL, 1988; 1990 e 1997).

Fundamentado no vínculo e na coresponsabilidade entre os profissionais de saúde e a população, o PSF tem como ponto de partida a família e seu entorno visando a transformação

A complexidade que envolve a interdisciplinaridade e a interinstitucionalidade constituiu-se em um desafio permanente para o grupo de docentes. A ousadia, a abertura para o novo, a persistência, a humildade, a cooperação e o respeito às singularidades foram atitudes e comportamentos que contribuíram para transpor as barreiras encontradas. gradativa da atual realidade sanitária.

Dentre os obstáculos de viabilização do PSF destacamos o perfil do profissional de saúde, cuja formação predominantemente baseada no modelo biomédico vigente, de maneira geral, não atende as diretrizes do programa. Desse modo, o Governo Federal vem estimulando os Estados na criação de Pólos de Capacitação, Formação e Educação Permanente de Pessoal para Saúde da Família, no qual destacamos o do Estado de Minas Gerais. O protocolo de intenções entre a Secretaria Estadual de Saúde e o Ministério de Saúde, iniciou-se em 1994 (Araujo, 1999), culminando com a efetivação da instalação de um Pólo sob a coordenação da Universidade Federal de Minas Gerais (PCFEP-SF da UFMG).

Atuando intensivamente no processo de capacitação de pessoal, o PCFEP-SF, da UFMG, compreende cinco linhas de ações: integração com os municípios e equipes de saúde, capacitação dos profissionais de nível universitário, capacitação do auxiliar de enfermagem e de agentes comunitários de saúde, inserção do PSF na graduação, e produção e incorporação de tecnologias apropriadas (MINAS GERAIS, 1998).

Em 1997, o PCFEP-SF, da UFMG, instituiu um convênio com a Faculdade de Medicina do Triângulo Mineiro (FMTM) de Uberaba, descentralizando, a partir de 1998, as atividades de capacitação do pessoal das regiões do Triângulo Mineiro e do Alto Paranaíba, para a FMTM.

Descrever a experiência dos Cursos Introdutórios do Programa de Saúde da Família na região do Triângulo Mineiro e do Alto Paranaíba constitui-se no objetivo deste trabalho.

\section{OPERACIONALIZAÇÃO DAS ATIVIDADES}

Constituiu-se um grupo de trabalho com representantes da FMTM - Docentes do Curso de Graduação em Enfermagem e Medicina, Diretoria Regional de Saúde (DRS) / Coordenadoria Regional do PSF e Secretaria Municipal de Saúde / Diretoria do Departamento de Saúde Pública, o qual iniciou

1 Profa. Assistente do Centro de Graduação em Enfermagem da FMTM, Uberaba - MG

${ }^{2}$ Profa. Doutora Visitante do Centro de Graduação em Enfermagem da FMTM, Uberaba - MG 
suas atividades participando do $1^{\circ}$ Encontro de Docentes de Saúde da Família, promovido pelo PCFEPSF da UFMG. Neste encontro discutiu-se o conteúdo temático, a metodologia, o planejamento, os critérios de avaliação, a programação e a operacionalização descentralizada dos Cursos Introdutórios em Saúde da Família para o ano de 1999 em Minas Gerais.

O grupo recém constituído, sob a coordenação do Centro de Graduação em Enfermagem, teve como ponto de partida a elaboração e a distribuição de um instrumento de coleta de dados para as equipes do PSF e Secretários Municipais de Saúde, dos municípios jurisdicionados à Delegacia Regional de Saúde (DRS) de Uberaba, a fim de elaborar o diagnóstico da atuação dos profissionais bem como, identificar o apoio logístico dos Secretários. Evidenciou-se a necessidade premente de capacitação profissional das equipes.

Nesta perspectiva, foi promovido o $1^{\circ}$ Seminário Regional do PSF em Uberaba com finalidade de uma discussão conjunta, entre a Universidade e os Serviços, para viabilizar a instalação dos referidos cursos.

Consolidaram-se, neste momento, os Cursos Introdutórios na região do Triângulo Mineiro. Capacitar, em especial, enfermeiros e médicos inseridos no PSF na reorientação e ou no início dos trabalhos em sua área de abrangência bem como, instrumentalizá-los à capacitação dos Agentes Comunitários de Saúde de suas equipes foram os objetivos estabelecidos (MINAS GERAIS, 1999).

O curso foi estruturado em três módulos, com carga horária total de 80 horas. Cada módulo foi desenvolvido mensalmente, organizado em períodos de concentração e de dispersão, procurando evitar, desta forma, o afastamento prolongado dos profissionais de suas atividades. Ao final de cada período de concentração, estabeleceu-se atividades a serem realizadas, pelo grupo, na sua área de atuação, possibilitando assim, a integralização do conhecimento à prática cotidiana. Foram ministrados cinco cursos nos municípios de Uberaba e Patos de Minas, no período de maio a novembro de 1999.

Os docentes que of ereceram os cursos, reuniram-se por diversas vezes, visando a integração e a coerência no desenvolvimento do conteúdo programático, definido pelo PCFEP-SF da UFMG. $O$ módulo I, Informação e análise dos princípios, conceitos e conjunturas do PSF, abordou temas relativos aos modelos explicativos do processo saúde-doença, modelos assistenciais, organização do PSF em Minas Gerais e introdução ao planejamento, com carga horária de 24 horas. No módulo ll, Introdução à organização dos serviços de saúde do PSF, trabalhou-se temas relacionados ao planejamento estratégico, em especial, o participativo local, diagnóstico de saúde e cadastramento familiar, totalizando 24 horas. O módulo III, Introdução à organização dos serviços de saúde do PSF e formação do agente comunitário de saúde (ACS), discutiu formas de instrumentalização para a capacitação do ACS, utilizando-se da metodologia problematizadora, perfazendo 32 horas.

Para a realização dos trabalhos em sala de aula, dois docentes atuaram como facilitadores. Buscou-se, de maneira participativa e compartilhada, estimular os grupos a serem agentes ativos na reconstrução e reflexão dos conteúdos abordados. Dentre as estratégias de ensino utilizadas destacamos: filmes seguidos de discussão, dinâmica de grupo, dramatização, desenho, estudo de caso, exposição dialogada.

A avaliação do curso ocorreu de forma gradativa e participativa, destacando três momentos. No primeiro utilizou-se um instrumento, composto de doze questões de múltipla escolha, elaborado pelo PCFEP-SF da UFMG, que avaliou o conhecimento cognitivo, aplicado no início e no término do curso. Em um segundo momento, realizou- se uma avaliação escrita, ao final dos dois primeiros módulos, buscando identificar a adequação dos objetivos ao desenvolvimento do curso. A última avaliação constituiu-se de um questionário semi estruturado, aplicado após o término do terceiro módulo. $O$ questionário contemplava a duração, o conteúdo e a metodologia de cada módulo.

\section{RESULTADOS}

Nos Cursos Introdutórios inscreveram-se 150 profissionais, destes 133 pessoas concluíram o curso, sete não compareceram e dez desistiram no decorrer do mesmo. Um estudo posterior pode ser realizado para identificar as causas da desistência, entretanto infere-se que um fator limitante pode ser decorrente da distância entre o município de origem dos profissionais e o da realização do curso. 
A clientela procedeu de 45 municípios de quatro DRS de Minas Gerais, como pode ser observada no Quadro 1.

QUADRO 1. Distribuição dos participantes dos Cursos Introdutórios, segundo a sua formação profissional e procedência, Uberaba, 1999.

\begin{tabular}{|l|c|c|c|c|}
\hline \multirow{2}{*}{ DRS } & \multicolumn{4}{c|}{ Formação profissional } \\
\cline { 2 - 5 } & Enfermeiro & Médico & Outras categorias & Total \\
\hline Uberaba & 32 & 26 & 11 & 69 \\
\hline Ituiutaba & 6 & 5 & 2 & 13 \\
\hline Patos de Minas & 25 & 6 & 6 & 37 \\
\hline Uberlândia & 18 & 2 & 3 & 23 \\
\hline Sem informação & - & 1 & - & 1 \\
\hline Total & $\mathbf{8 1}$ & $\mathbf{4 0}$ & $\mathbf{2 2}$ & $\mathbf{1 4 3}$ \\
\hline
\end{tabular}

No quadro acima, verifica-se que $56,6 \%$ dos participantes são enfermeiros, $28 \%$ médicos e $15,4 \%$ de outras categorias, dentre as quais odontólogo, psicólogo, assistente social e cargos administrativos na DRS.

Verificou-se que $74,1 \%$ dos participantes são do sexo feminino. O predomínio das mulheres nas equipes do PSF, pode ser também observado nos dados apresentados pelo Ministério da Saúde, representando a enfermagem $90,9 \%$ e a medicina $44,0 \%$, excetuando a região sul, cujo percentual de mulheres $(51,9 \%)$, ultrapassa o quantitativo dos homens (BRASIL, 2000).

Quanto a faixa etária cabe assinalar que $54,6 \%$ dos participantes enquadravam-se entre 30 a 49 anos. Estes dados aproximam-se dos achados do Ministério da Saúde, no qual a maior concentração dos profissionais médicos e enfermeiros inseridos no PSF, situa-se na faixa etária entre 30 e 49 anos, representada por $62,4 \%$ (BRASIL, 2000).

Concernente aos resultados da primeira avaliação, relativo a aplicação do teste de conhecimento cognitivo, verificou-se que o número de acertos em até seis questões obteve-se um percentual de $28,9 \%$ no pré e de $23,8 \%$ no pós teste, valores bem próximos, o mesmo acorrendo com acertos em 7 , $8,9,10,11$ e 12 questões, como pode ser observada na Tabela 1.

TABELA 1. Distribuição da avaliação do pré e pós teste dos Cursos Introdutórios, segundo o número de acertos das questões. Uberaba, 1999.

\begin{tabular}{c|c|c|c|c}
\hline $\mathbf{N}^{\circ}$ de acertos & \multicolumn{2}{|c|}{ Pré-teste } & \multicolumn{2}{c}{ Pós-teste } \\
\hline das questões & $\mathbf{N}$ & $\mathbf{N}$ & $\mathbf{~}$ & 23,8 \\
\hline Até $\mathbf{6}$ & 39 & 28,9 & 31 & 17,7 \\
\hline $\mathbf{7}$ & 21 & 15,6 & 23 & 16,9 \\
\hline $\mathbf{8}$ & 29 & 21,5 & 22 & 19,2 \\
\hline $\mathbf{9}$ & 24 & 17,8 & 25 & 12,3 \\
\hline $\mathbf{1 0}$ & 13 & 9,6 & 16 & 8,5 \\
\hline $\mathbf{1 1}$ & 7 & 5,2 & 11 & 1,5 \\
\hline $\mathbf{1 2}$ & 2 & 1,5 & 2 & $\mathbf{1 0 0 , 0}$ \\
\hline Total & $\mathbf{1 3 5}$ & $\mathbf{1 0 0 , 0}$ & $\mathbf{1 3 0}$ & \\
\hline
\end{tabular}

Esperava-se maior índice de acertos no pós-teste, entretanto aplicando o teste do c2 aos valores da Tabela 1, encontrou-se o valor de 3,09 ( $p=0,79)$, não significativo. Quanto ao teste utilizado, duas situações podem ser destacadas, a primeira de ter sido simplesmente ao acaso e a segunda a impossibilidade do teste em detectar mudanças comportamentais. Considerando que a metodologia utilizada está centrada nestas mudanças, que necessitam de tempo, reflexão e é influenciada pela historia de vida pessoal, e não somente no conhecimento cognitivo imediato, reconhece-se a limitação do teste utilizado. 
Com a avaliação obtida, ao término dos dois primeiros módulos, identificou-se pontos que contribuíram na reformulação dos cursos subsequentes. De modo geral, as sugestões de mudanças estavam centradas especialmente em alterações na estratégia de ensino e ênfase em determinados conteúdos, considerados significativos para o grupo.

Os resultados da última avaliação foram categorizados, a priori, em ótimo, regular, extenso e outros. Os mesmos mostraram que a duração, o conteúdo e a metodologia foram $84,6 \%, 81,5 \%$ e $86,6 \%$ de ótimos, respectivamente. Reconhece-se que além da avaliação no decorrer do curso, faz-se necessário o acompanhamento das atividades dos egressos. Para tanto, encontra-se em fase de planejamento uma nova avaliação, objetivando captar possíveis transformações ocorridas na praxis profissional dos egressos estimuladas pelo trabalho desenvolvido no curso introdutório.

\section{CONSIDERAÇÕES FINAIS}

A proposições atribuídas pelo Ministério da Saúde, para o treinamento introdutório, são entre outras, a flexibilidade em buscar uma adequação entre recursos disponíveis e a necessidade das equipes, a sensibilização dos profissionais para desenvolver um trabalho em parceria com a comunidade e a possibilidade dos mesmos apreenderem e compreenderem os indicadores do sistema de informação da atenção básica (SIAB). Posto isto, considera-se que a realização destes cursos permitiu a instrumentalização das equipes para a organização inicial do seu processo de trabalho, compreensão ampliada do processo saúde-doença e possibilidade de intervir nas práticas assistenciais.

Cabe assinalar que, o trabalho no PSF pressupõe o envolvimento de equipe multiprofissional e da comunidade, bem como articulação intersetorial, que possibilitem intervenções em saúde, visando também melhorias no meio ambiente natural e social. Para tanto, recomenda-se a educação permanente de todos os membros da equipe, assim como da comunidade, objetivando as transformações almejadas pelo programa.

A complexidade que envolve a interdisciplinaridade e a interinstitucionalidade constituiu-se em um desafio permanente para o grupo de docentes. A ousadia, a abertura para o novo, a persistência, a humildade, a cooperação e o respeito às singularidades foram atitudes e comportamentos que contribuíram para transpor as barreiras encontradas.

Através das parcerias foi possível a somatória dos recursos financeiros, materiais e humanos. Coube à FMTM, a coordenação e execução do Curso Introdutório; à DRS, o processo de seleção e recrutamento dos participantes e às Secretarias Municipais de Saúde, o apoio financeiro para transporte e estada, assim como a liberação dos profissionais. Ao PCFEP-SF da UFMG, o apoio financeiro e pedagógico, essenciais ao desenvolvimento dos cursos.

Face ao exposto, pode-se dizer que foi possível uma articulação de complementaridade entre o saber e o fazer, levando o grupo a acreditar que o PSF pode contribuir para a transformação desejada.

Assinala-se que, no contexto atual, os Cursos Introdutórios ainda se apresentam como uma etapa extremamente válida para uma primeira aproximação com a filosofia do PSF, porém se reconhece a necessidade de maior aprofundamento através do Cursos de Especialização.

\section{REFERÊNCIAS BIBLIOGRÁFICAS}

ARAUJO, M.R.N. A Saúde da Família: Construindo um novo paradigma de intervenção no processo saúdedoença. São Paulo, 1999. 141p. Tese (Doutorado) - Escola de Enfermagem da Universidade São Paulo.

BRASIL. Constituição, 1988. Constituição da República Federativa do Brasil, 1988. São Paulo, Ed. Revista dos Tribunais, 1989.

BRASIL. Lei 8080, de 19 de setembro de 1990. Dispõe sobre as condições para promoção, proteção e recuperação da saúde, a organização e o funcionamento dos serviços correspondentes. Diário Oficial da União, Brasil, 20 set.1990. Seção I. 
BRASIL. Ministério da Saúde. Secretaria de Assistência à Saúde. Coordenação de Saúde da Comunidade. Saúde da Família: uma estratégia para a reorientação do modelo assistencial. Brasilia: Ministério da Saúde, 1997. 36p.

BRASIL. Ministério da Saúde. Fundação Osvaldo Cruz. Perfil dos médicos e enfermeiros do programa de saúde da família no Brasil. Brasília, 2000. 146 p., v.1.

MINAS GERAIS. Universidade Federal de Minas Gerais. Secretaria do Estado de Saúde de Minas Gerais. Faculdade de Medicina da UFMG. Escola de Enfermagem da UFMG. Escola de Saúde de Minas Gerais. Curso de Especialização em Saúde da Família - Equipes de Saúde da Família - Médicos e Enfermeiros. Belo Horizonte, 1998. Texto mimeografado.

MINAS GERAIS. Universidade Federal de Minas Gerais. Pólo de Capacitação e Educação Permanente de Pessoal para Saúde da Família. (PCEP-SF/UFMG) - Ministério da Saúde Subprojeto de Capacitação de Profissionais de Nível Universitário. Curso Introdutório para Médicos e Enfermeiros das equipes básicas do PSF. Belo Horizonte, 1999. Texto mimeografado.

\section{Grupo de trabalho}

Faculdade de Medicina do Triângulo Mineiro

Profa. Darlene M. S. Tavares; Profa. Helena H. Iwamoto; Profa. Dra. Iranilde J. M. Mendes; Profa. Marina P. R. Oliveira; Profa. Maria Isabel B. M. Saúde; Prof. Dr. Renato H. Fabri e Profa. Dra. Sandra A. Pinheiro.

Secretaria Municipal de Saúde de Uberaba: Dra. Gisele P. Morais.

Diretoria Regional de Saúde de Uberaba: Sra. Luzimar R. D. Ishimura.

Coordenação: Profa. Helena H. Iwamoto.

\section{Apoio}

Pólo de Capacitação, Formação e Educação Permanente da Saúde da Família da UFMG Profa. Dra. Elza S. Erichsen; Prof. Horácio de Faria, Profa. Dra. Janete Ricas, Profa. Maria José C. C. G. Brant e Profa. Marília R. da Silveira.

Coordenação: Profa. Maria José C. C. G. Brant.

Coordenadoria Estadual do PSF da SES / MG

Coordenação: Profa. Dra. Maria Rizoneide N. de Araujo. Ministério da Saúde 